\title{
REGRESSION OF BOTH ORAL MUCOCELE AND PAROTID SWELLINGS, FOLLOWING ANTIRETROVIRAL THERAPY: CASE REPORT
}

Dr Kabunda Syebele. MBChB; BChD; MChD(MFOSurgery) - Medical Officer / Lecturer. Department of Maxillofacial and Oral Surgery - Oral \& Dental hospital-, University of Pretoria - South Africa.

Corresponding address:

Dr Kabunda Syebele

Oral and Dental hospital

Department of Maxillofacial

and Oral Surgery

University of Pretoria

P O Box 1266

Pretoria 0001

South Africa

E-mail: kabunda.syebele@up.ac.za

Cell. No:027824144130(H), Tel. No:027123192551 (W), Fax No: 027123192172 / 3 (W)

\begin{abstract}
HIV-salivary gland associated disease is a well accepted concept in the HIV-related literature. Parotid swellings, especially in its cystic benign lymphoepithelial form, have been largely reported. Oral mucoceles (ranulas) were also associated with HIV in some publications. The exact nature of this link between mucoceles and HIV is still to be clarified. The mainstream treatment of most of parotid pathologies and oral mucoceles remains surgical approach. Strong evidences do, however, exist about lymphopithelial lesions of parotid glands that have been successfully treated with antiretroviral drugs. We
\end{abstract}


present a case of intraoral mucocele, coexisting with bilateral parotid gland lymphoepithelial lesions, on a 2-year-old HIV-positive patient. Both parotid gland swellings and the sublingual mucocele have completely regressed following antiretroviral therapy. No surgical intervention was required. Conversely to benign lymphoepithelial lesions of parotid glands, the regression of oral mucocele on HIV-positive patient, following antiretroviral drugs therapy appears to be a rare phenomenon.

Keywords: Oral mucoceles - parotid swellings - antiretroviral therapy

\section{INTRODUCTION}

HIV- salivary gland associated disease (HIV-SGD) is a well accepted concept in HIV literature. ${ }^{1,2}$ Benign lymphoepithelial lesions (BLEL) of parotid salivary glands are among the most commonly described BLEL. ${ }^{2-4}$ These lesions appear more often in the early stage of HIV infection, and may be its first manifestation. There is no universally accepted treatment for BLEL of parotid glands. Different modalities of treatment for BLEL have been suggested in the literature. Superficial parotidectomy and low-dose radiotherapy were advocated for in the early days. ${ }^{5,6}$ Simple observation, fine needle aspiration as well as sclerotherapy have also been suggested, with variable results.,7 Finally, BLEL of parotid glands have been reported to respond dramatically well to antiretroviral therapy (ART). Benign lymphoepithelial lesion of parotid glands have, under ART, regressed to almost their original size in some cases (Fig 1 A,B). ${ }^{8-10}$

The association of oral mucoceles (ranulas) with HIV infection has already been reported in the literature. ${ }^{11-13}$ The exact pathogenesis of this relationship between these two different pathologies remains, however, unclear. 


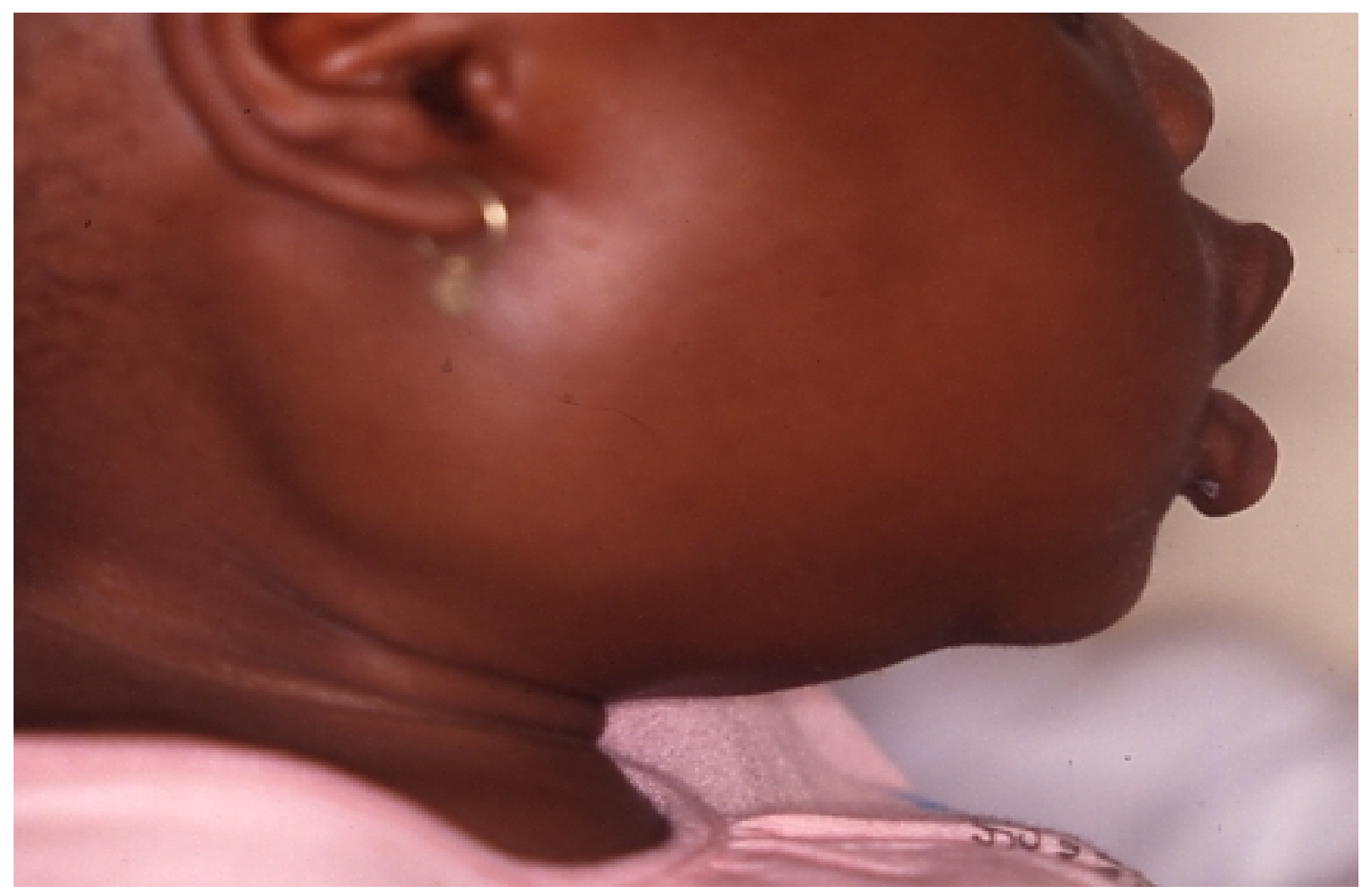

Fig. 1A

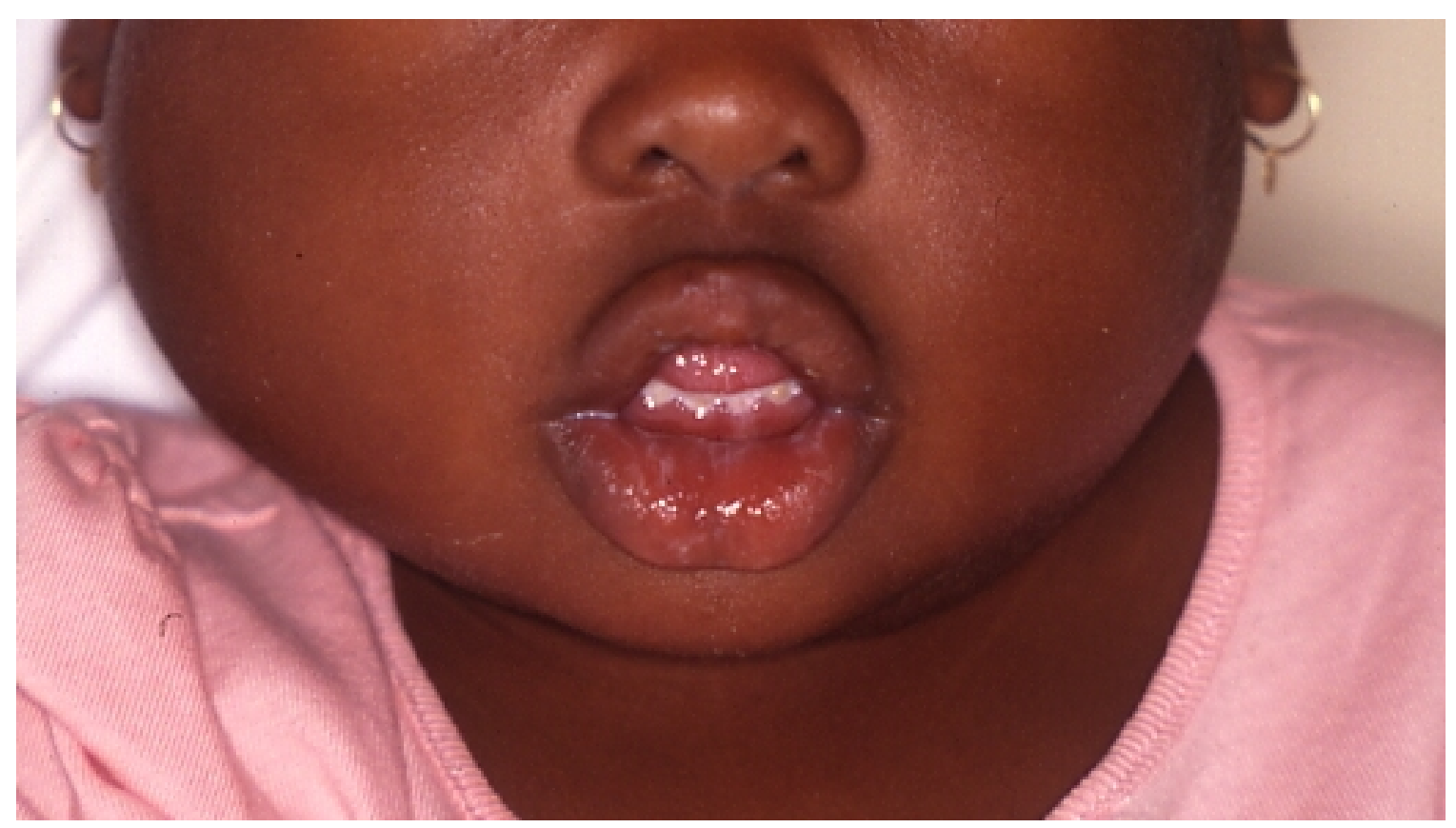

Fig. 1B.

Fig. 1A and 1B. Massive swelling of parotid gland in a pediatric HIV-positive patient. (A) Right side and (B) bilateral view. 
Several modalities of treatment for oral mucoceles have been also described: laser excision $^{14}$, cryosurgery, sclerotherapy ${ }^{15}$, and marsupialization. Radical surgery of the cystic lesion and / or the attached salivary gland is by far the most accepted standard

mode of management. ${ }^{16,17}$ Little is, however, known about the effect of ART on oral mucoceles. This report presents a case of an intraoral (floor of the mouth) mucocele, in a HIV-positive young patient that, with the associated bilateral cystic benign lymphoepithelial lesions of the parotid glands, has completely regressed, following antiretroviral drugs therapy.

\section{CASE REPORT}

A 2-year-old girl was brought to the out patients clinic of the Maxillofacial Surgery department with the complaint of a slow growing, bilateral parotid gland swelling, as well as the presence of a small growth in the floor of the mouth, that was interfering with the normal process of feeding and speech. The medical history revealed that she was a known HIV-positive patient, and she just completed her treatment against pulmonary tuberculosis (PTB). Physical examination noted the presence of large bilateral parotid gland swellings (Fig.1 A and 1B), which were slightly tender on palpation. The intraoral examination revealed the presence of a cystic lesion in the right floor of the mouth, which characteristics corresponded clinically to that of an oral mucocele. There was no history of any other congenital growth. A fine needle aspiration was performed on the intraoral lesion, and yielded approximately $2.5 \mathrm{ml}$ of amber and mucus-like fluid, consistent with a salivary gland origin of the intraoral lesion. A computerized tomography scanner (CT Scan) examination demonstrated multilocular images in line with cystic benign lymphoepithelial lesions of parotid glands (Fig. 2A and 2B). A fine needle aspiration of 


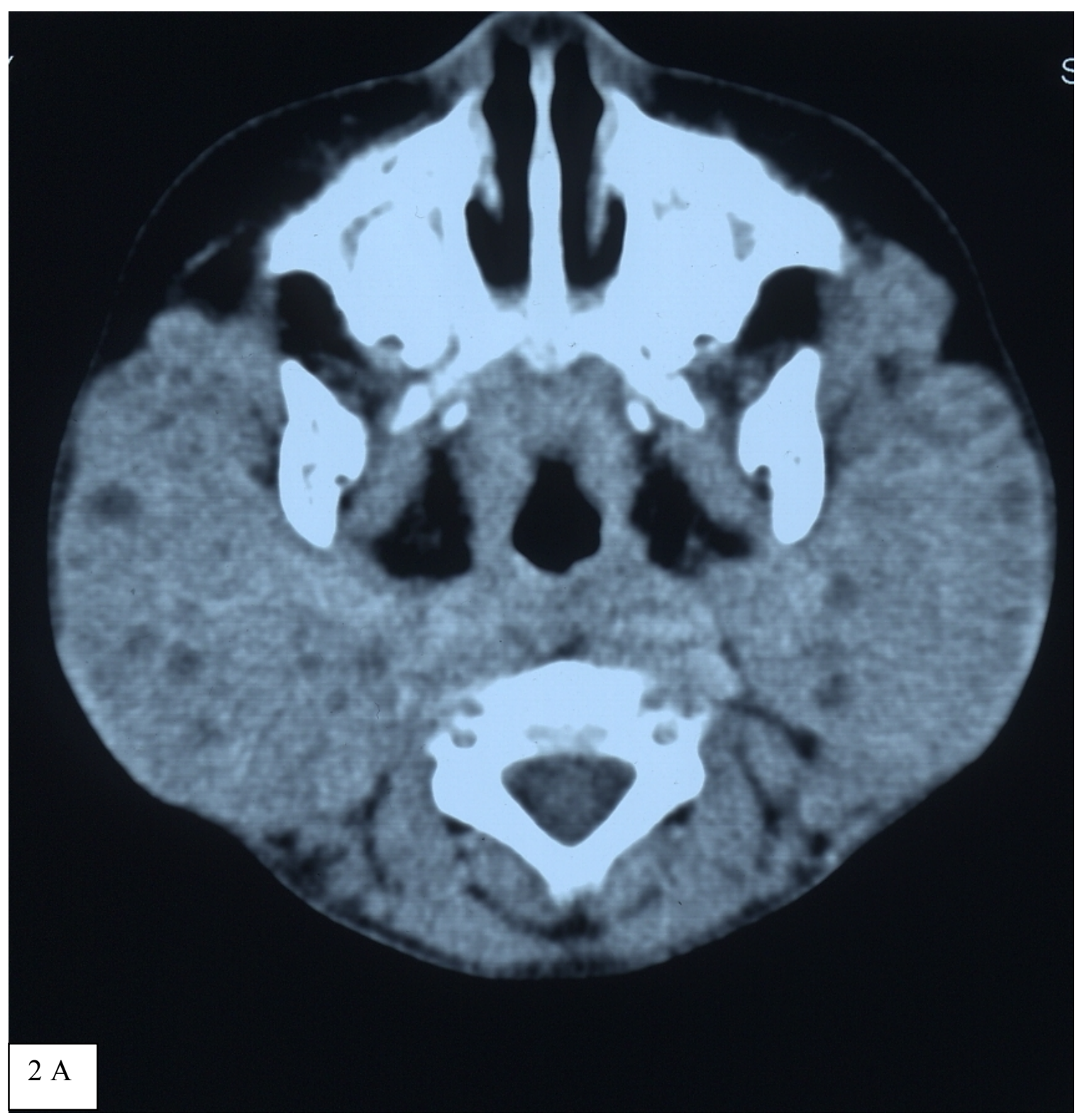

Fig. 2 A 


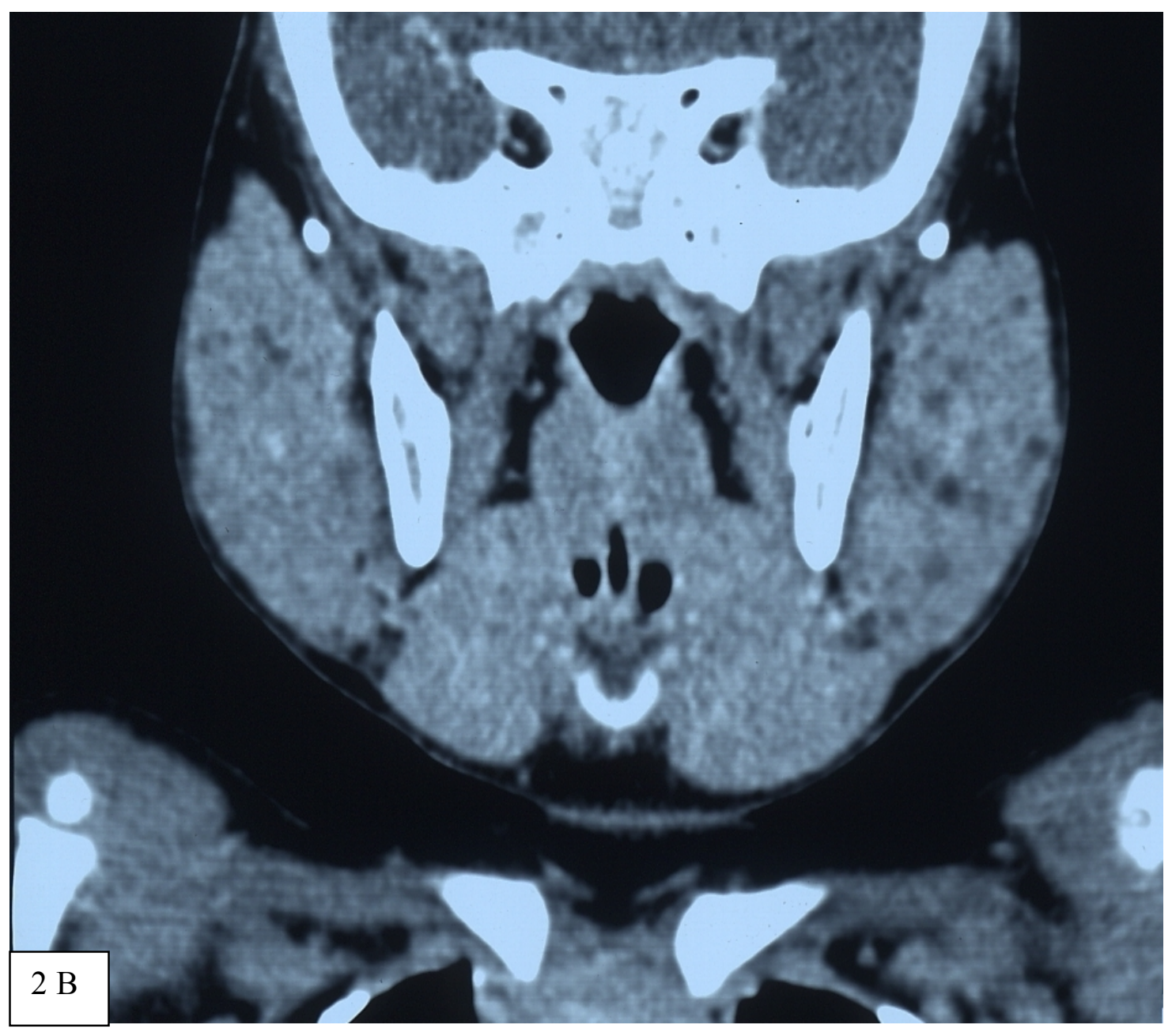

Fig. 2 B

Fig. 2A and 2B. Radiological expression of BLEL on CT scan, (A) axial and (B) coronal, of parotid glands of the patient in Fig.1.

parotid gland was also performed, and the fluid was sent for cytology study. The cytological report did not show the presence of any abnormal cells, and suggested strongly a possible benign lymphoepithelial lesion of parotid glands. The treatment with antiretroviral drugs was initiated, based on the percentage of CD4 T-cell $(<20 \%)$. The parotid gland swellings, as well as the cystic lesion in the floor of the mouth completely regressed three months after the beginning of ART (Fig 3A and 3B). CT Scan examination performed at six months follow up, confirmed the physical reduction of 


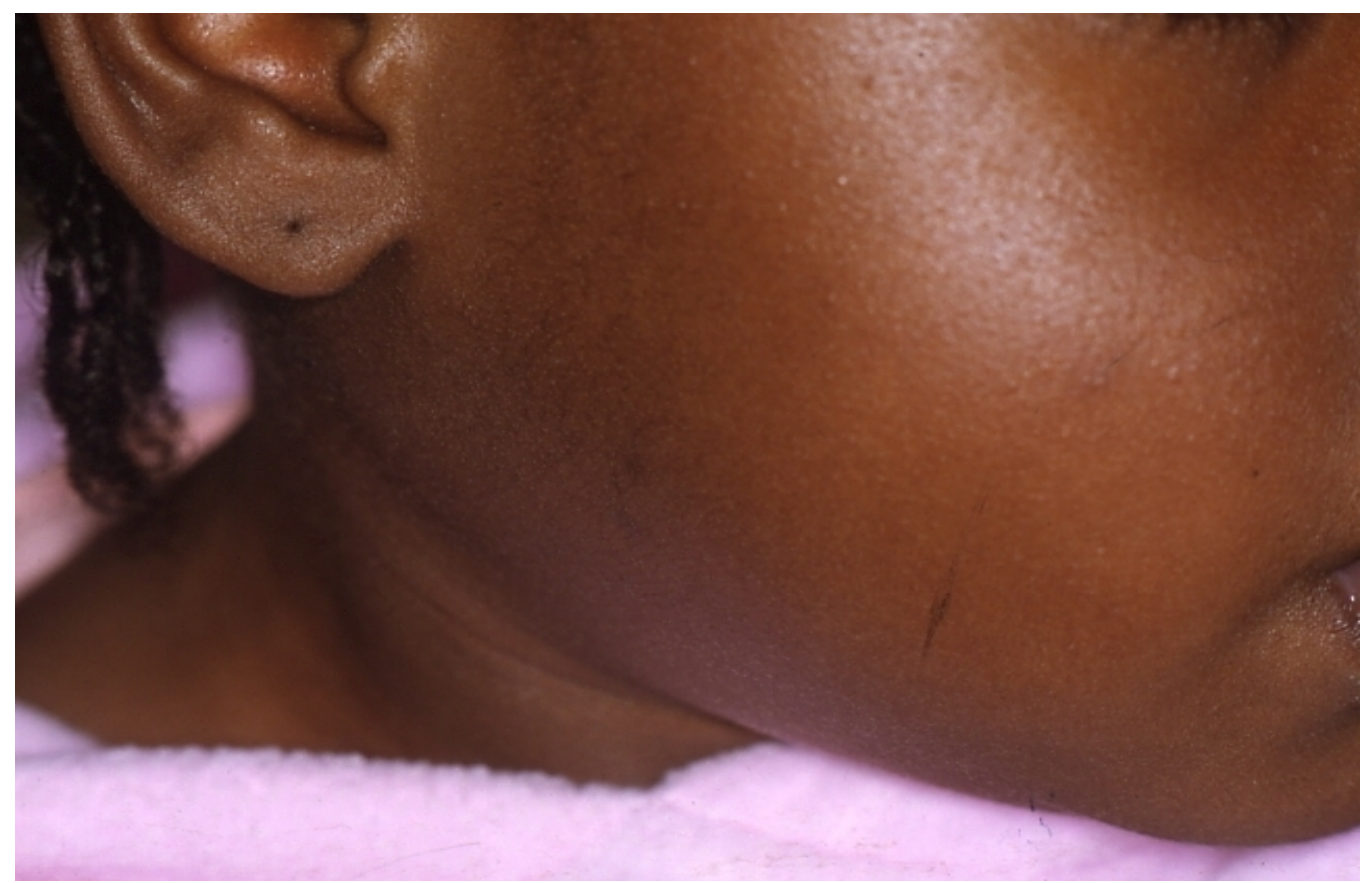

Fig. 3A

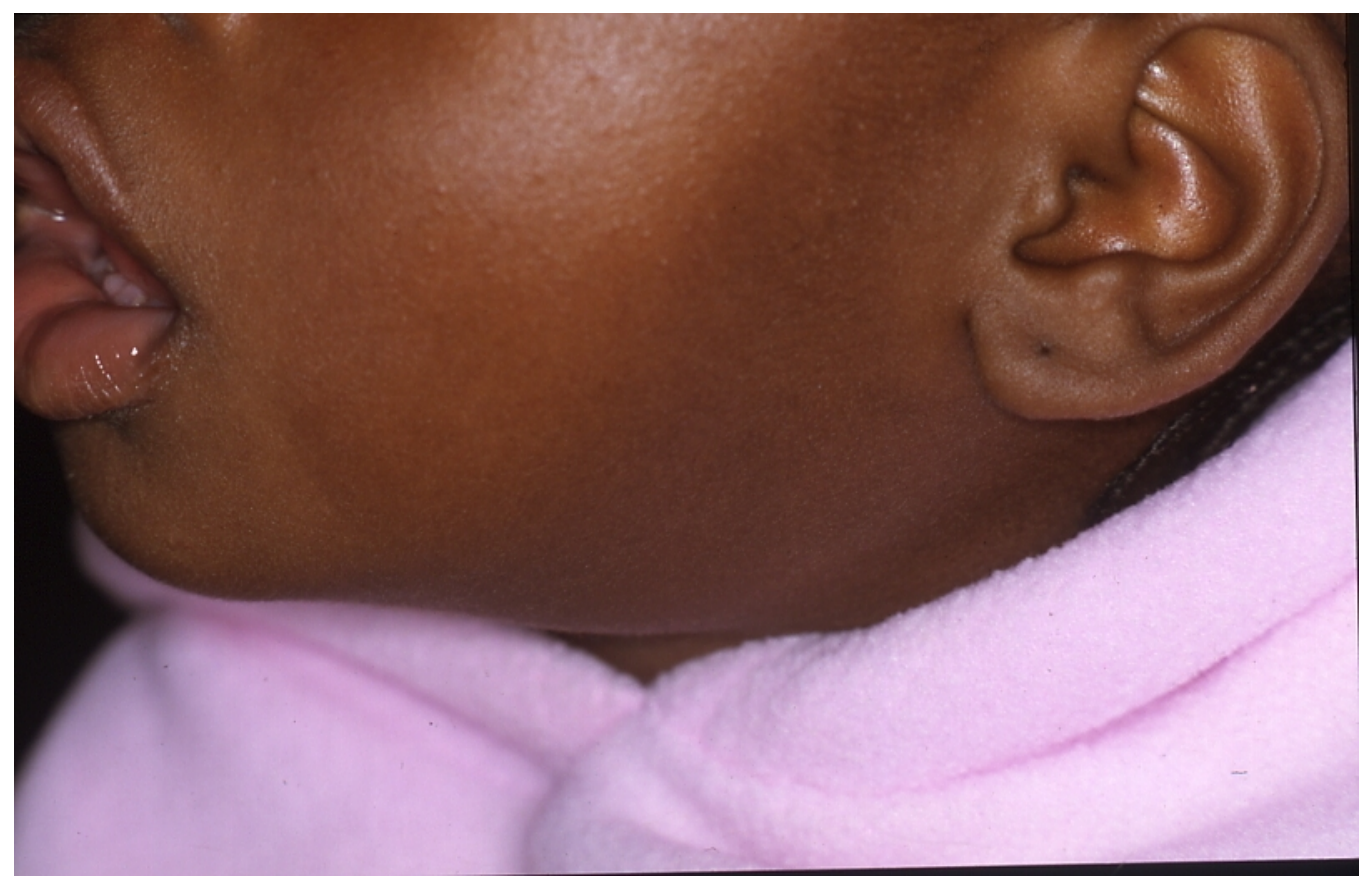

Fig. 3B

Fig. 3A and 3B. Clinical appearance of the very same patient shown in fig. 1, three months after the start of antiretroviral therapy.(A) right side and (B) left side. 


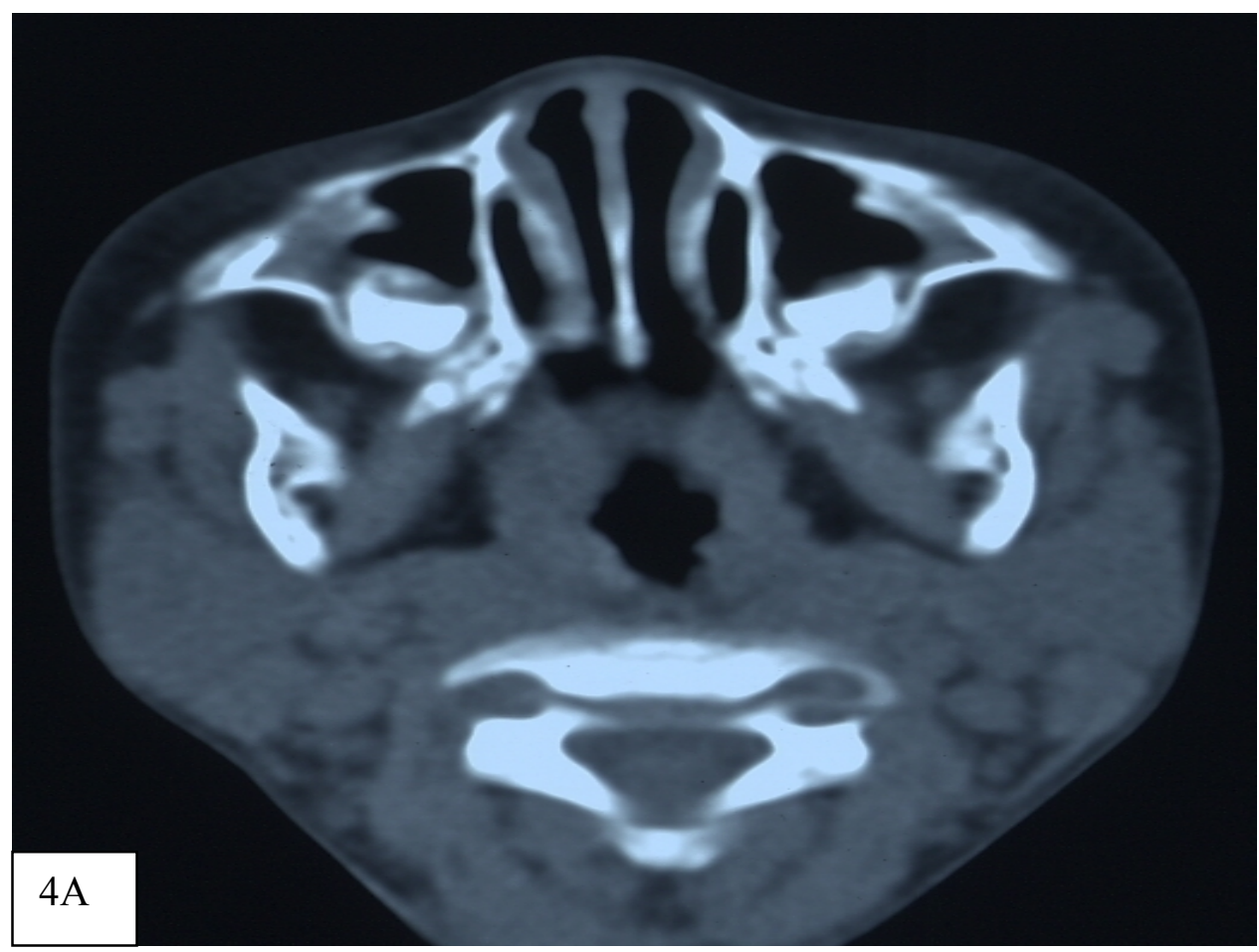

Fig. 4A

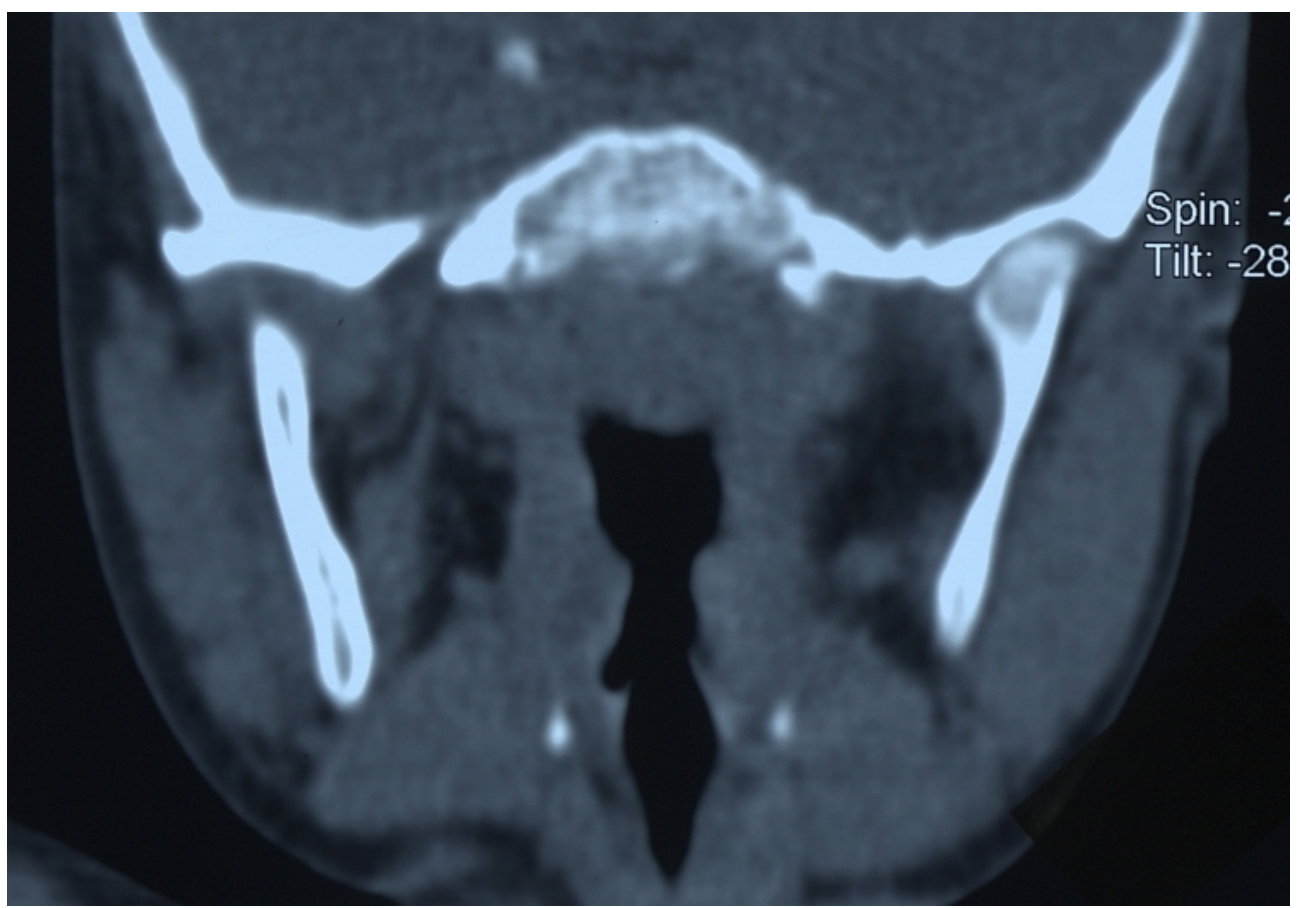

Fig. 4B.

Fig. 4A and 4B. Radiological confirmation, six months after the ART, of the spectacular reduction of parotid salivary glands. (CT scan: $\mathrm{A}=\mathrm{axial}$ view; $\mathrm{B}=$ coronal view). 
parotid glands (Fig. 4A and 4B). The patient, now 4-year-old, has since been clinically free of any salivary gland lesion (Fig. 5).

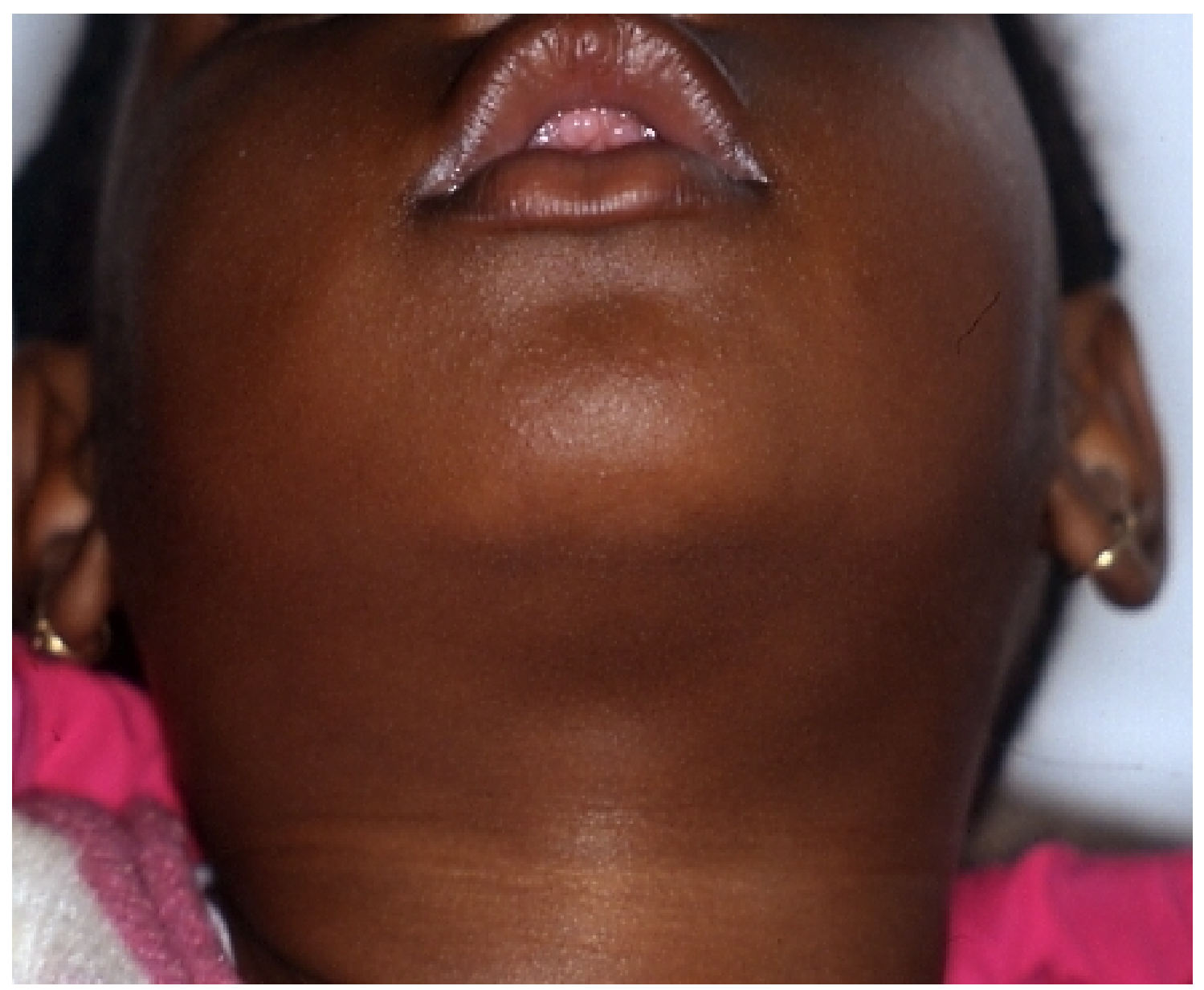

Fig. 5. Two years follow up under ART, patient presents no sign of any salivary gland disease.

\section{DISCUSSION}

Oral mucoceles are common lesions of the oral cavity. ${ }^{18,19}$ The etiology is traditionally believed to be linked to previous trauma in minor salivary gland bearing areas. ${ }^{18,19} \mathrm{We}$ usually prefer the term of "mucocele" in absence of any histological report confirming either the extravasation phenomenon, or the retention cyst.

The association of mucoceles (ranula) and HIV-infection has been mentioned in the literature. ${ }^{11-13}$ Chidzonga $^{12}$ has reported $88.5 \%$ of HIV-infected patients among 38 cases 
of ranula. He further raised the question of considering mucoceles as a HIV/AIDS associated oral lesion. A positive answer to this later question would imply a sort of paradigm shift on the treatment planning for mucoceles on HIV-positive patients, taking in consideration for example, the very positive and spectacular response of BLEL to antiretroviral therapy.

The treatment of mucoceles is currently based on a surgical approach, irrespective of the histological type. Different authors have proposed variety of modified surgical procedures, but there is a generally accepted consensus on the excision of associated salivary gland with or not the excision of the cystic lesion. ${ }^{16-19}$ Sclerotherapy $^{15}$ and the use of botulism toxin ${ }^{20}$ are also presented as alternative to surgery for the treatment of mucoceles with promising results. The regression of an oral mucocele following ART, as reported in this paper suggests the possibility of a medical treatment for mucoceles on HIV-positive patients. Indeed there is already a high level of expectation generated by the effect of ART on BLEL of parotid glands on HIV-positive patients. Cases of substantial, if not complete regression of parotid gland swellings following ART have been well documented in the literature. ${ }^{8-10}$ It would be of great benefit for HIV-positive patients to be spared of any elective and invasive surgical procedures such as parotidectomy or excision of the ipsilateral sublingual or submandibular salivary glands. These complex surgical procedures are not without complications. Special caution needs to be exercised during these operations to avoid an unsightly facial scar and to preserve the facial and the lingual nerves as well as the salivary gland duct (Wharton). ${ }^{13,16,18,21,22}$ The young age of some patients is also an important factor to be considered. If the result we have observed in this case is effectively related to the ART, then the link between HIV infection and 
mucoceles, including ranulas, may be consolidated, and the possibility of causative relationship may be hypothesized.

We need to bring to the attention of the readers the fact that the complete resolution of the intraoral mucocele in this case may also not be attributed exclusively to the effect of ART. Some mucoceles are short-lived lesions that rupture and heal by themselves. ${ }^{18,19}$ Zhi et al., have reported in their publication two cases of ranula that did not recur following fine needle aspiration and observation for six months. ${ }^{23}$ One possible explanation for such results is that, after spontaneous rupture or fine needle aspiration, usually done with large needle in the case of thick mucus, a permanent fistula may be created and provide thus a new exit orifice for the accumulated saliva. Such a scenario may be considered in case of small and superficial mucoceles that can, time and again, spontaneously rupture and heal or recur. ${ }^{18,19}$ The difference with the case we have observed is based on the size of the lesion, the location in the floor of the mouth, and most importantly on the overall pattern of the involution of the oral mucocele, concomitantly with the parotid gland swellings. No further recurrence has been observed at two-year follow up. The rate of recurrence for ranulas is reportedly very high following simple drainage or marsupialisation. ${ }^{18}$ It would not be, therefore, an over statement to consider that the regression of the oral mucocele as presented in this paper, may be included in the specific context of the interaction between ART and HIVassociated salivary gland diseases in HIV-infected patients. 


\section{CONCLUSION}

It is generally accepted that benign lymphoepithelial lesions of parotid glands on HIVpositive patients are part of HIV-SGD. It is also well documented that ART has a real therapeutic effect on the parotid gland swellings on HIV-positive patients. It is not, however, completely clear at this stage that mucoceles are also part of HIV-SGD. Further more the response of oral mucoceles to ART is not known. Further studies on the interaction between oral mucoceles, including ranulas, with HIV infection are, therefore, needed, not only to clarify the nature of relationship between HIV and mucoceles, but also to ascertain the possible effect of ART on these lesions.

\section{REFERENCES}

1. Scully C, Davies R, Porter S, Eveson J, Luker J. HIV-salivary gland disease. Salivary scintiscanning with technetium pertechnetate. Oral Surg Oral Med Oral Path Oral Radiol Endod. 1993;76:120-123.

2. Mulligan R, Navazesh M, Komaroff E, Greenspan D, Redford M, Alves M, et al. Salivary gland disease in human immunodeficiency virus-positive women from the WIHS study. Oral surg Oral Med Oral pathol Oral radiol Endod. 2000;89:702-709.

3. Dave SP, Pernas FG, Roy S. The benign lymphoepithelial cyst and a classification system for lymphocytic parotid gland enlargement in the pediatric HIV population. Laryngoscope. 2007;117:106-113.

4. Rosso R, Pretolesi F, Del Bono V, Buscaglia M, Ferrando S, Farinella ST, et al. Benign lymphoepithelial parotid lesion in vertically HIV-infected patients. AIDS Patient Care ST. 2006;20:536-541. 
5. Marx RE, Stern D. Oral and Maxillofacial Pathology: a rationale for diagnosis and treatment. Illinois: Quintessence Publishing Co, Inc; 2003: p524-526.

6. Goldstein J, Rubin J, Silver C, Meritz K, Chao C, Ting J, et al. Radiation therapy as a treatment for benign lymphoepithelial parotid cysts in patients infected with human immunodeficiency virus-1. Int J Radiat Oncol Bio Phys. 1992;23:1045-1050.

7. Marcus A, Moore CE. Sodium murrhuate sclerotherapy for treatment of benign lymphoepithelial cysts of parotid gland in HIV patient. Laryngoscope. 2005;4:746-749.

8. Mandel L , Surattanont F. Regression of HIV parotid swellings after antiviral therapy: case reports with computed tomographic scan evidence. Oral Surg Oral Med Oral Pathol Oral Radiol Endod. 2002;94:454-459.

9. Owotade FJ, Fatusi OA, Adebiyi KE, Ajike SO, Folayan MO. Clinical experience with parotid gland enlargement in HIV infection: a report of five cases in Nigeria. J Contemp Dent Pract. 2005;6:136-145.

10. Ehrenstein BP, Mir J, Duncan RA, Stram JR, O'Hara CJ, Craven DE. Management of lymphoepithelial parotid cysts in HIV-infected adults. Compr Ther. 2000;26:25-30.

11. Chidzonga MM, Rusakaniko S, Ranula: another HIV/AIDS associated oral lesion in Zimbabwe? Oral Dis. 2004;10:229-232.

12. Chidzonga MM, Mabomva L. ranula: experience with 83 cases in Zimbabwe. J Oral Maxillofac Surg.2007;65:79-82.

13. Hershkin AT, Miller Jr EJ. Plunging ranula in young HIV patient. NY State Dent J 2007;73:46-47.

14. Zola M. Laser for treatment of ranula. J Oral Maxillofac Surg. 2007;65:1271. 
15. Roh J-L, Kim HS. Primary treatment of pediatric plunging ranula with nonsurgical sclerotherapy using Ok-432 (picibanil $\left.{ }^{\mathbb{R}}\right)$. Int j Pediatr Otorhi.

(2008),doi:10.1016/j.ijport.2008.06.003.

16. Zhao YF, Jia Y, Chen XM, Zhang WF. Clinical review of 580 ranulas. Oral surg Oral Med Oral pathol Oral radiol Endod. 2004;98:281-287.

17. McGurk M. Management of the ranula. J Oral Maxillofac Surg. 2007;65:115-116.

18. Flaitz CM, Hicks MJ. Mucocele and ranula. Available fromURL:

http://emedicine.medscape.com/article/1076717-overview.

19. Neville BW, Damm DD, Allen CM, Bouquot JE. Oral and maxillofacial pathology.

$3^{\text {rd }}$ ed. St Louis: Saunders; 2009.p. 453-459.

20. Chow TL, Chan SWW, Lam SH. Ranula successfufully treated by botulinum toxin type A: report of 3 cases. Oral surg Oral Med Oral pathol Oral radiol Endod. 2008;105:41-42.

21. Scianna JM, Petruzzelli GJ. Contemporary management of tumors of salivary glands. Curr Oncol Rep. 2007; 8: 134-138.

22. Zhao Y-F, Jia J, Jia Y. Complications associated with surgical management of ranulas. J Oral Maxillofac Surg 2005;63:51-54.

23. Zhi K, Wen Y, Ren W, Zhang Y. Management of infant ranula. Int j Pediatr Otorhi. 2008;72:823-826. 